\title{
Sobre o ensino da língua inglesa no currículo escolar por repercussões do programa ciência sem fronteiras
}

\author{
Eliana Santiago Gonçalves Edmundo ${ }^{1}$ \\ José Marcelo Freitas de Luna ${ }^{2}$
}

\begin{abstract}
RESUMO: A falta de proficiência na língua inglesa pode ser tomada como um obstáculo para a participação de estudantes brasileiros no Programa Ciências sem Fronteiras. Por parâmetros internacionais de avaliação, a qualidade do aprendizado deste idioma na educação básica do Brasil apresenta-se como muito baixa, fato que é repercutido em canais midiáticos. Focando, especificamente, em reportagens da mídia digital que abordam a qualidade da aprendizagem de língua inglesa no Brasil nos últimos três anos e nos dispositivos legais que normatizam o ensino de língua estrangeira na educação básica, o presente texto examina o descompasso entre o status da língua inglesa frente às demandas de internacionalização do ensino superior no país e o estatuto desse idioma expresso nas políticas públicas educacionais para a educação básica brasileira. Os resultados apontam para os discursos que se estabelecem socialmente e, assim, influenciam as iniciativas que se podem relacionar àquelas de políticas linguísticas.
\end{abstract}

Palavras-chave: Políticas linguísticas. Língua Inglesa. Programa Ciências sem Fronteiras.

\section{On the english language teaching in the school curriculum by science without borders program impact}

\begin{abstract}
The lack of English proficiency can be taken as an obstacle to the participation of Brazilian students in Science Without Borders Program. For international valuation parameters, the quality of learning this language in basic education in Brazil presents itself as too low, a fact that is reflected in media channels. Focusing specifically on the digital media reports that address the quality of the English language learning in Brazil in the last three years and the legal rules that regulate the foreign language teaching in basic education, this paper examines the mismatch between the status of the English language meet the demands of internationalization of higher education in the country and the status of that language expressed in the public educational policies for the Brazilian basic education. The results point to discourses that are established socially and thus influence the initiatives that can relate to those of language policies.
\end{abstract}

Keywords: Language policies. English language. Science Without Borders Program.

${ }^{1}$ Doutoranda em Educação pela Universidade do Vale do Itajaí e mestre em Letras - Estudos Linguísticos pela Universidade Federal do Paraná (2010); é professora no curso de Letras e Pedagogia na Faculdade de Administração, Educação, Ciências e Letras e professora de língua inglesa na rede pública no Estado do Paraná. E-mail: eliana_edmundo@yahoo.com.br.

${ }^{2}$ Doutor em Linguística pela Universidade de São Paulo, com estágio sanduíche na Universidade de Cambridge e pós-doutorado pela Universidade do Texas (2011); é professor e pesquisador do Programa de Pós-Graduação (Mestrado e Doutorado) em Educação da Universidade do Vale do Itajai. E-mail: mluna@univali.br. 


\section{Revista Letras Raras}

ISSN: 2317-2347 - Vol. 7, Ano 4, No 2 - 2015

\section{INTRODUÇÃO}

A constatação de que o aprendizado de língua inglesa tem sido um obstáculo à participação de brasileiros nos cursos ofertados no exterior tem levado o tema aos canais midiáticos, desde o lançamento do programa Ciência sem Fronteiras (doravante CsF) em 2011, pelo governo federal. Com base no baixo desempenho de estudantes em avaliações internacionais, diversas reportagens veiculadas na TV, nos jornais e nas mídias sociais têm reiterado as deficiências no aprendizado dessa língua estrangeira. A divulgação do levantamento realizado pela empresa especializada em intercâmbios, English First ${ }^{3}$, acerca dos índices de proficiência em inglês em diversos países, motivou a publicação de diversas notícias na mídia nacional, relatando a baixa qualidade da proficiência dos brasileiros. Segundo o English Proficiency Index ${ }^{4}$, após testar 1,7 milhões de pessoas em 2012, das quais 130 mil são residentes no Brasil, o país ocupava a $46^{a}$ posição em um ranking que considerou cinquenta e quatro países, perdendo quinze posições no índice, em relação à pesquisa realizada no ano anterior. Já em 2013, a posição do Brasil subiu para $38^{\circ}$ entre 63 países, permanecendo assim em 2014. Os testes são realizados online por usuários da internet e, embora não sejam oficiais, as amostras têm sido suficientemente representativas para a formação de opinião pública.

Por outro lado, no âmbito das políticas públicas no Brasil, tramita no Congresso Nacional um projeto de reformulação do ensino médio. No que se refere ao ensino de línguas, uma nova proposta apresentada em julho de 2014 sugere a alteração da LDB 9394/96, exigindo a fluência na oralidade no ensino da língua estrangeira moderna de oferta obrigatória no currículo escolar, a partir do sexto ano do ensino fundamental.

\footnotetext{
${ }^{3}$ Disponível em: http://www.ef.com.br. Acesso em: 23 Out. 2014.

${ }^{4}$ Índice de proficiência de Inglês promovido pela English First.
} 


\section{Revista Letras Raras}

ISSN: 2317-2347 - Vol. 7, Ano 4, No 2 - 2015

Segundo a notícia no Portal do Senado 5 , o autor do projeto de lei entende que a fluência oral é um objetivo necessário no ensino de língua. Entende, também, que a população menos favorecida financeiramente não tem acesso a esse conhecimento, uma vez que é fornecido a partir da iniciativa privada, voltando-se para as camadas privilegiadas da sociedade. $\mathrm{O}$ relator reconhece que somente a declaração em Lei não assegura que esse objetivo seja atingido, mas que a ação consiste num esforço do legislador para mudar a inércia que domina o ensino de língua estrangeira nas escolas brasileiras.

Já no contexto universitário, o governo federal instituiu o Inglês sem Fronteiras (doravante IsF) no ano de 2012. O principal objetivo desse programa é incentivar o aprendizado da língua inglesa, bem como oferecer a possibilidade de aperfeiçoamento do idioma aos candidatos à bolsa de estudo do CsF. Em 2014, o governo federal lançou o programa Idiomas sem fronteiras (doravante ISF), visando complementar o CsF e as demais políticas públicas de mobilidade estudantil e acesso a universidades de países onde a educação superior é conduzida em idioma estrangeiro.

As referências até aqui feitas, quais sejam, as notícias publicadas sobre o desempenho dos estudantes brasileiros, bem como sobre as iniciativas governamentais podem ser tomadas como características da carência de políticas linguísticas. O que parece haver são medidas de compensação ou de preenchimento de lacunas na formação dos estudantes egressos do ensino médio, expostas pelos resultados de testes internacionais de proficiência dos candidatos ao CsF. O que não parece haver são medidas direcionadas para a melhoria do ensino nas etapas de escolarização da educação básica em escolas regulares. Por exemplo, o acesso à plataforma virtual do curso My English Online 6 (doravante MEO), vinculado ao programa IsF, é destinado a um público restrito que são os estudantes de

\footnotetext{
${ }^{5}$ Disponível em: < http://www12.senado.gov.br/noticias/materias/2014/07/09/fluencia-oral-podera-serexigida-no-ensino-de-lingua-estrangeira-em-escolas-publicas> Acesso em 15 fev. 2015.

${ }^{6}$ Disponível em:< http://www.myenglishonline.com.br/>. Acesso em 17 Fev 2015.
} 


\section{Revista Letras Raras}

ISSN: 2317-2347 - Vol. 7, Ano 4, No 2 - 2015

universidades privadas que obtiveram nota igual ou superior a 600 pontos em edição do Enem após 2009, alunos de IES públicas ou alunos de programa de pós-graduação stricto sensu (Mestrado e Doutorado) recomendado pela CAPES. Já os cursos ofertados pelo programa ISF são destinados à formação de estudantes, professores, corpo técnico-administrativo de instituições de ensino superior (doravante IES), e professores de idiomas da rede pública de educação básica.

A situação do ensino e do aprendizado da língua inglesa no Brasil é objeto de muitos estudos acadêmico-científicos, eles abordam o baixo sucesso na aprendizagem de inglês na educação básica nas últimas décadas, não se restringindo ao setor público. Pesquisadores como Moita Lopes (2003); Rajagopalan (2003); Gimenez (2006); Jordão (20077); Menezes de Souza (2011), para citar alguns, têm trazido contribuições significativas e esclarecedoras para pensar sobre isso e, inclusive, apontam que essas são questões importantes para uma agenda de pesquisa na área. Por sua vez, há vários pesquisadores que apresentam perspectivas de ensino de superação da conjuntura ora caracterizada, por meio de experiências documentadas em relatos de pesquisas, como os trabalhos de Duboc $(2007,2012)$, Takaki (2008), Edmundo (2013), para citar alguns. São pesquisadores que discorrem sobre a construção de práticas pedagógicas locais de ensino de língua inglesa, tendo em vista as transformações ocorridas na última década, que alteraram completamente as práticas sociais, e indicam a necessidade de novas políticas linguísticas para o ensino desse idioma.

Diante das repercussões do Programa CsF para o ensino de inglês no Brasil, o presente trabalho examina o descompasso entre o status desse idioma frente às demandas de internacionalização do ensino superior no país e o estatuto do inglês nas políticas públicas educacionais para a educação básica na escola regular. Para a consecução do objetivo, realizamos um levantamento de dados, selecionando reportagens que circulam na mídia digital e abordam a aprendizagem de língua inglesa no Brasil (no período entre 2012 e 2015) e averiguando iniciativas governamentais para o ensino da língua estrangeira na educação básica, desde o 


\title{
Revista Letras Raras
}

ISSN: 2317-2347 - Vol. 7, Ano 4, No 2 - 2015

lançamento do programa CsF. Esses dados são importantes porque caracterizam a língua inglesa e disponibilizam visões alternativas que reforçam o discurso dominante sobre o ensino de inglês no Brasil. Essa relevância também é entendida por Gimenez (2006), ao declarar que

\begin{abstract}
os discursos da mídia veiculam mitos relacionados à eficácia ou não do ensino, e como essas concepções se tornam um termômetro para as escolhas de cursos de línguas e dos critérios de eficácia desse ensino. Essas imagens acabam também por invadir as salas de aula, nas metáforas e representações que os alunos trazem, e que, via de regra, acabam por direcionar os objetivos que professores estabelecem. (GIMENEZ, 2006, p. 252).
\end{abstract}

O artigo está organizado da seguinte forma: primeiramente, apresentamos os programas CsF, IsF e ISF, sob ponto de vista das instâncias que os conceberam e os sustentam. Depois, examinamos os artigos publicados na mídia, entre 2012 e 2014, que tecem comentários relevantes acerca dos parâmetros de qualidade de ensino de inglês na educação básica a partir do lançamento do CsF. Apresentamos, na sequência, as políticas expressas no dispositivo legal que pretende promover a reformulação curricular do ensino médio, ainda em tramitação no Congresso Nacional. Em seguida, discutimos as evidências encontradas à luz de estudos de Rajagopalan (2003), Calvet (2007), Luna e Sehnem (2013), Oliveira (2013, 2013b), Spolski (2004) e Shohamy (2006) para, então, tecermos as considerações finais.

\section{APRESENTANDO OS PROGRAMAS}

O Decreto presidencial n. 7642/2011 instituiu o CsF com o objetivo de propiciar "a formação e a capacitação de pessoas com elevada qualificação em universidades, instituições de educação profissional e tecnológica, e centros de pesquisa estrangeiros de excelência". O Programa também busca "atrair para o Brasil jovens talentos e pesquisadores estrangeiros de elevada qualificação, em áreas de conhecimento definidas como prioritárias (BRASIL, 2011, Art. 1²)”. Cabe aos Ministros de Estado da 


\section{Revista Letras Raras}

ISSN: 2317-2347 - Vol. 7, Ano 4, No 2 - 2015

Educação e da Ciência, Tecnologia e Inovação dispor sobre as áreas prioritárias de atuação do programa, as instituições brasileiras e estrangeiras participantes, os benefícios auferidos em cada uma das modalidades de bolsas, as metas e indicadores de desempenho dos candidatos e demais regras para a implementação do programa por meio de editais.

Para atender aos objetivos do programa, a CAPES e o CNPq propõem a concessão de dois tipos de bolsas: (i) bolsas de estudos para estudantes brasileiros em instituições no exterior, nas modalidades: graduação-sanduíche; educação profissional e tecnológica; doutorado-sanduíche; doutorado pleno; pós-doutorado e (ii) bolsas no Brasil para pesquisadores visitantes estrangeiros e jovens talentos. Essas bolsas são ofertadas a estudantes de engenharia e todas as áreas tecnológicas, além das ciências biológicas, visando promover a consolidação, expansão e internacionalização da ciência, da tecnologia e da inovação, conforme determina o decreto.

Quando implementado, o governo federal previu a concessão de até $75 \mathrm{mil}$ bolsas de estudos para alunos de graduação (que tenham cumprido entre 20\% e 90\% do currículo do curso) e de pós-graduação stricto sensu, em um período de quatro anos. Em 2014, já haviam sido concedidas aproximadamente 83 mil bolsas, e a meta era atingir 101 mil até o final daquele ano. Para a segunda fase ${ }^{7}$ do programa, esperase atingir mais de 100 mil bolsas ofertadas entre os anos de 2015 e 2018.

Um dos principais requisitos para participar do CsF é a proficiência em uma língua estrangeira, que deve ser comprovada a partir de exames internacionais de nivelamento. A língua inglesa é o idioma requerido para a maior parte das bolsas, exigido também por países que não têm esse idioma como língua nativa, como Japão, Coreia do Sul, Bélgica, Alemanha e Itália.

A dificuldade na proficiência na língua tem sido responsável pela exclusão de milhares de candidatos ao Programa. Como estratégia, que pode ser referida como

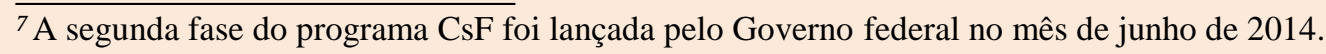




\section{Revista Letras Raras}

ISSN: 2317-2347 - Vol. 7, Ano 4, No 2 - 2015

de superação, o governo federal criou o IsF no ano de 2012. Destinado aos estudantes de graduação e de pós-graduação de universidades públicas e privadas, o IsF abrange ações específicas, a saber: ensino de inglês online (MEO), aplicação gratuita de teste de nivelamento e proficiência (TOEFL- ITP) e ensino presencial de língua inglesa.

A Portaria n⿳⺈ 1.466/2012 regulamenta o programa IsF, definindo "a formação e capacitação de alunos de graduação das instituições de educação superior para os exames linguísticos exigidos para o ingresso nas universidades anglófonas" como principal objetivo da iniciativa (BRASIL, 2012, Art. 1º). Desde que surgiu, já foram ofertadas seis rodadas de aplicação de testes a candidatos ao CsF em universidades credenciadas, além de uma oferta de aulas presenciais para alunos de graduação e pós-graduação. A gratuidade dos testes abrange somente estudantes e servidores de universidades e institutos federais.

Para complementar, o Governo Federal desenvolveu o programa ISF no final do ano de 2014. A Portaria n. 973/2014 deu materialidade à iniciativa que tem como objetivo:

propiciar a formação e a capacitação em idiomas de estudantes, professores e corpo técnico-administrativo das Instituições de Educação Superior Públicas e Privadas - IES e de professores de idiomas da rede pública de educação básica, bem como a formação e a capacitação de estrangeiros em língua portuguesa. (BRASIL, 2014, p.11-12)

Nos termos da Portaria, haverá incentivo à formação presencial e virtual em diferentes idiomas, devendo a seleção dos candidatos ao programa ser feita por editais específicos. As línguas oferecidas são: inglês, francês, espanhol, italiano, japonês, mandarim, alemão e português para estrangeiros. Para o desenvolvimento do ISF, serão feitos acordos com órgãos e entidades do governo, da mesma maneira que poderão ser utilizadas parcerias já firmadas no âmbito do programa CsF e de outras políticas públicas de internacionalização. 


\section{REPORTAGENS DA MÍDIA DIGITAL}

Historicamente, a mídia impressa conquistou a credibilidade e a confiança dos leitores do mundo ocidental, que tem a escrita como fundamental instrumento de circulação e de pertencimento de ideias e de conhecimento, conforme as reflexões de Rodrigues (2012). Há que se observar, no entanto, o grande poder que o texto escrito exerce sobre o leitor; a diagramação, os destaques, o estilo, o vocabulário, a estratégia discursiva, a autoria são alguns dos elementos que, por vezes, influenciam no modo de expor uma informação e, consequentemente, na maneira que será interpretada pelo leitor.

Com a mídia digital não é muito diferente. De modo implícito, quase imperceptível, os novos tipos de retórica multimídica também seduzem, induzindo desejos, concepções, generalizações, verdades. Como defende Levy (2011), "as dimensões emocionais e estéticas (indissociavelmente ligadas) das mensagens, bem como projeções de identidade que as acompanham, muitas vezes contribuem mais para moldar as subjetividades políticas que os argumentos racionais" (idem, p. 47).

O exposto faz-se importante, tendo em vista que os primeiros contatos com as reportagens que serão apresentadas se deram pela mídia social Facebook. Fomos receptores de diversas postagens ao longo dos últimos três anos e motivados a realizar a leitura dos artigos na íntegra, dada a relevância do tema. Embora as nossas reflexões e sentidos sobre eles não estejam aqui expostos, as percepções, como tinha que ser, estão impressas nos critérios de seleção dos dados e nos excertos deles extraídos.

Assim, para o levantamento de dados, foram selecionados os artigos publicados em portais institucionais do programa CsF, IES, Portal da Câmara dos deputados, páginas virtuais de jornais e revistas. O rastreamento do material com informações complementares para a pesquisa foi realizado exclusivamente pela internet em site de busca, com ênfase em palavras ou expressões relativas ao tema em questão. Os 
elementos desejados foram averiguados em publicações no período compreendido entre o mês de abril de 2012 e o mês de fevereiro de 2015. Vejam-se os excertos:

Quadro 1: Trechos dos artigos selecionados ${ }^{8}$.

a) Em abril de 2012 o Jornal Gazeta do Povo publicou o artigo com a seguinte manchete "É difícil aprender inglês na escola" seguida da seguinte lide:

Número de alunos por sala, método de ensino ineficiente e professores sem fluência no idioma dificultam o aprendizado.

b) Em setembro de 2012, o Jornal O Globo publicou a manchete "Brasileiros não sabem falar inglês: apenas 5\% dominam o idioma" com a lide:

Pesquisa mostra que só $36 \%$ do grupo que se declara fluente tem verdadeiras habilidades com a língua estrangeira.

c) Em outubro de 2012, a BBC publicou o artigo "Brasileiros falam inglês de 'qualidade muito baixa', diz pesquisa". O artigo transcreve trechos do relatório de pesquisa da English Proficiency Index, já referenciado neste artigo, tecendo os seguintes comentários:

Menos inglês significa menores inovação, comércio e receita (...) Educação pública tem um papel importante nisso. E, embora haja mudanças no Brasil, elas são recentes e não sabemos ainda qual será o impacto sobre o aprendizado de inglês.

d) Em fevereiro de 2013, a manchete “Governo diminui exigência de inglês no Ciência sem Fronteiras" do Jornal Estadão anuncia que:

Por conta do nível insatisfatório do inglês e da alta taxa de reprovação dos estudantes que concorrem a bolsas do programa Ciência sem Fronteiras no Reino Unido, governo brasileiro, embaixada britânica e a Universities UK (entidade que faz o intermédio na relação dos bolsistas com as instituições) decidem reduzir a pontuação mínima exigida nos exames de proficiência. [...] De acordo com o jornal O Estado de S. Paulo, o TOEFL, um dos exames de certificação mais aceitos pelo programa, exigia uma pontuação mínima de 72 pontos nas quatro modalidades da prova (compreensão auditiva, leitura, escrita e fala). Agora, com a flexibilização, a exigência caiu para 42 pontos. [...] Já o IELTS, outro exame utilizado na seleção, pedia do estudante uma pontuação de 5,5 nas quatro modalidades. Agora, 4,5 em duas habilidades já é suficiente para que ele seja considerado apto ao intercâmbio .

e) Em fevereiro de 2013, o Guia do Estudante publicou a manchete “Ciências sem Fronteiras exigirá nível menor de conhecimento em inglês" com o texto:

\footnotetext{
${ }^{8}$ Grifo nosso, assim como todos os outros desta seção.

${ }^{9}$ Disponível em:<http://noticias.universia.com.br/destaque/noticia/2013/02/07/1003952/governodiminui-exigencia-ingles-no-ciencia-sem-fronteiras.html>. Acesso em: 5 maio 2015.
} 
ISSN: 2317-2347 - Vol. 7, Ano 4, No 2 - 2015

Das 4 mil bolsas oferecidas pelo programa na Grã-Bretanha, apenas 1,8 mil foram preenchidas por falta de candidatos com inglês satisfatório.

f) Em março de 2013, a Revista Educação publicou o artigo "Inglês se aprende na escola?, seguido do lide:

Por que as salas de ensino regular não são reconhecidas como locais onde é possível aprender uma língua estrangeira? Novos programas de formação docente tentam mudar esse cenário.

g) Em março de 2013, outro artigo publicado na Revista Educação com o título

"Brasileiros falam mal o inglês", apresenta o lide:

Pesquisa aponta que Brasil está em $46^{\circ}$ lugar, do total de 54 países, no que se refere ao domínio da língua inglesa.

h) Em março de 2013, o Portal da Câmara dos deputados federais publicou a reportagem:

"Especialistas reclamam de deficiência no estudo de língua estrangeira no ensino médio" com o seguinte trecho:

O aluno está na aula de língua estrangeira, mas aquilo que ele está aprendendo não tem nenhuma relação com o que ele vai usar no seu dia a dia.

i) Em outubro de 2013, o Portal da Unicamp publicou a notícia "Inglês dificulta internacionalização" contendo falas da Vice-Reitoria de Relações Institucionais e Internacionais da IES, Waldenor Moraes, como segue:

A escola pública ensina muito genericamente o verbo 'to be'. E quando este estudante entra na universidade, ela coloca a reponsabilidade na sua mão: 'você não sabe inglês, então se vire'. E aí o aluno vai se virando. E assim ele sobrevive na graduação, só que quando chega o momento em que precisa produzir, ele se depara com esta realidade. É uma responsabilidade, portanto, do ensino médio, mas a universidade não pode também virar as costas.

j) A manchete "Domínio de inglês é problema também para classe 'A"” foi publicada em fevereiro de 2015 pelo Jornal Folha de São Paulo com a seguinte lide:

Fala inglês fluentemente quem tem dinheiro para pagar um curso particular ou para estudar fora do país, certo? Errado.

De maneira geral, a problemática abordada nos artigos foi a do nível insatisfatório de conhecimentos de língua inglesa dos candidatos a bolsas do CsF. É importante frisar que na pesquisa realizada não identificamos, no período investigado, nenhuma reportagem publicitária que se reportasse a experiências de sucesso e de resultados satisfatórios no ensino de línguas de línguas. 


\section{Revista Letras Raras}

ISSN: 2317-2347 - Vol. 7, Ano 4, No 2 - 2015

Como defende Gimenez (2006), importa os efeitos de mensagens publicitárias como estas apresentadas no campo do ensino de línguas, e sobre isso passamos a tecer comentários. Essa delimitação tem como pressuposto que toda manifestação de linguagem é carregada de ideologia na sua essência (FIORIN, 2004; BAKHTIN, 1999). Sem aprofundar nessa questão, mas lançando luz à análise, consideramos que as publicidades, ao veicularem argumentos sobre o perfil ideal do professor de inglês, a metodologia eficaz da aprendizagem, os objetivos do conhecimento de um idioma, influenciam as representações e visões de mundo de sujeitos, grupos e coletividades inteiras. Tais ideais promovem o inglês a um estatuto de mercadoria, uma commodity desejável e que permite obter sucesso e prestígio social no mundo (JORDÃO, 2004; EDMUNDO, 2013).

Sobre a naturalização dos discursos publicitários, Pouza (2001) esclarece que as estratégias discursivas utilizadas pela mídia escrita visam dar autenticidade aos fatos e refletem sobre as representações dos discursos no campo do ensino. Segundo o autor,

\footnotetext{
importa para as agências midiáticas é menos o caráter de verdade das informações veiculadas. Ao contrário, avaliamos ser o objetivo central a criação de formas coercitivas que pretendem, através da aparente neutralidade da materialidade dos discursos, impor uma representação unívoca, monoglóssica (Menezes de Souza, 1994, 1995), das concepções de (...) melhor método, escola e professor de línguas. (POUZA, 2001, p. 147).
}

Algumas consequências dessas representações citadas pelo autor, no contexto de ensino, dizem respeito à influência que exercem na construção de políticas linguísticas. Os sentidos produzidos pela mídia provocam interpretações que podem ocultar o papel social do ensino de línguas estrangeiras e a função social da língua inglesa na tomada de decisões.

\section{POLÍTICAS PÚBLICAS PARA O ENSINO DE LE}




\section{Revista Letras Raras}

ISSN: 2317-2347 - Vol. 7, Ano 4, No 2 - 2015

As políticas públicas na educação envolvem a articulação de projetos que abarcam o Estado e a sociedade. Como nos ensina Freire (1998), são elementos que demonstram a preocupação do país com o seu futuro. Nesse sentido, influenciam a vida das pessoas enquanto direcionadoras na construção de uma escola, de um currículo, de práticas pedagógicas, de conhecimento e de sujeitos.

No que diz respeito ao ensino de línguas estrangeiras no contexto escolar, requer pensá-las em conjunto com políticas linguísticas. A esse respeito, Rajagopalan (2003) esclarece que "o conhecimento das políticas linguísticas é fator crucial para melhor entender, lidar e ensinar as línguas que fazem parte do nosso contexto" (SILVA et al, 2011). O termo cunhado por Calvet (2007) ampara este argumento, na medida em que define política linguística como "grandes decisões referentes às relações entre as línguas e a sociedade ${ }^{e}$. Nessa ótica, compreendemos que seja preciso colocar a tônica sobre aspectos negligenciados nas decisões políticas sobre as línguas para que se possam pensar, por exemplo, em os usos das línguas estrangeiras na sociedade brasileira.

Tem-se, portanto, que a LDB (Lei de Diretrizes e Bases da Educação Nacional no 9394/96) é uma regulamentação que reflete uma política para o ensino de línguas e organiza a atuação governamental por meio de ações práticas e concretas (OLIVEIRA, 2010). Assim, com o advento da referida Lei, foi estabelecida uma nova configuração para o ensino de línguas estrangeiras no currículo escolar. A partir desse novo ordenamento, o ensino de língua estrangeira moderna passou a ser obrigatório no currículo escolar a partir da $5^{\mathrm{o}}$ série $^{10}$, deliberando à comunidade escolar a responsabilidade de escolha do idioma, desde que disponível pela instituição de ensino. Estabeleceu-se ainda que, no ensino médio, pode ser incluída uma segunda língua, em caráter optativo, dentro das condições da instituição. Além disso, permite que o ensino desse componente curricular possa ser organizado em

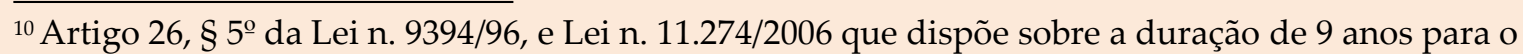
ensino fundamental.
} 


\section{Revista Letras Raras}

ISSN: 2317-2347 - Vol. 7, Ano 4, No 2 - 2015

turmas, com alunos de séries distintas, com níveis equivalentes de adiantamento na matéria, sinalizando a possibilidade de a escola dividir as turmas com base no nível de domínio do idioma e não mais com alunos de níveis de desempenho heterogêneos.

Fundamentalmente, a Lei propõe alterações significativas no âmbito estrutural e pedagógico da educação básica, embora muitas ações não tenham sido efetivamente implementadas até a presente data. Por exemplo, a garantia da qualidade do ensino prevista na legislação parece estar longe de ser vivenciada. Resultante da efetivação das mudanças estabelecidas desde a publicação da referida Lei, e considerando os prazos para a sua regulamentação, passados mais de quinze anos a aprendizagem de língua inglesa na escola regular continua apresentando resultados insatisfatórios.

O quadro observado é preocupante e, guardando coerência com o cenário, o Projeto de Lei no․ 6840/2013, atualmente em tramitação no Congresso Nacional, propõe alterar a LDB 9394/96, num projeto de ampla reformulação do ensino médio. Nesta investida, despontam iniciativas de políticas para o ensino de línguas estrangeiras, a saber:

a) Criação de uma comissão para estudar e definir um referencial de níveis de desempenho esperados em línguas estrangeiras ao término do ensino fundamental 1, ensino fundamental 2, ensino médio e da Licenciatura em Letras para o ensino de línguas (vinculada ao Ministério da Educação).

Instituição de equipe para implementação de um exame nacional para certificação do desempenho dos aprendizes de línguas estrangeiras nos diferentes níveis.

c) Implementação da Lei n. 11.161, de 2005, uma vez que o prazo para oferta da língua espanhola em todas as escolas de ensino médio do país terminou em agosto de 2010 sem que essa determinação seja cumprida.

d) Realização de concursos com bancas de aferição de capacidade comunicativa para admissão de professores de línguas estrangeiras em todo o país. (BRASIL, 2013).

Sobre o exposto, cabe assinalar que as medidas tencionadas pelas instâncias governamentais incidem na quantificação da qualidade da aprendizagem de línguas 


\section{Revista Letras Raras}

ISSN: 2317-2347 - Vol. 7, Ano 4, No 2 - 2015

estrangeiras e na avaliação da formação inicial de professores, como forma de superação das deficiências. Entretanto, os entraves do ensino de línguas de qualidade, muito além de avaliações de desempenho, são reconhecidamente outros, como afirma Gadotti (2013): investimento na qualificação de professores, organização do tempo e espaço escolar para o estudo de línguas, vida do estudante, condições de trabalho do professor, para citar alguns.

É importante também considerar que a escola lida essencialmente com a formação humana e esta não pode ser mensurada e nem controlada por resultados. "A preparação básica para o trabalho e a cidadania do educando" é a finalidade da educação básica da escola regular, estabelecidas pela LDB $^{11}$. Portanto, além da aquisição de conhecimentos linguísticos, espera-se que o ensino possa proporcionar uma oportunidade para que os estudantes "reflitam sobre o seu próprio contexto e sobre as suposições epistemológicas e ontológicas suas e dos outros", emprestando a acepção de cidadania mundial cunhado por Andreotti (2014, p.64), como uma possibilidade de interpretação da referida Lei. Concordando com Libâneo (2011), a política que visa objetivos pragmáticos e instrumentais serve à lógica de mercado, associada aos critérios de produtividade e competitividade, sem repercussão expressiva na função social das línguas.

Retomando a referência ao projeto em tramitação, no início de 2013 a respectiva comissão convida o linguista Almeida Filho (2014), dentre outros estudiosos para expor sobre os "fatores relacionados ao público e notório fracasso do processo de ensino-aprendizagem de língua estrangeira nas escolas do ensino médio do nosso país" e apresentar, "de acordo com seus respectivos entendimentos, quais as alternativas de soluções para o referido fracasso" ${ }^{12}$. No encontro, Almeida Filho (idem) sugeriu que o ENEM, atualmente com apenas cinco questões de língua

\footnotetext{
${ }^{11}$ Artigo 26, § 5o da Lei n. 9394/96, e Lei n. 11.274/2006 que dispõe sobre a duração de 9 anos para o ensino fundamental.

${ }^{12}$ Conforme conta em ementa do requerimento apresentado à Câmara em 7 de março de 2013.Disponível $<$ http://www.camara.gov.br/proposicoesWeb/fichadetramitacao?idProposicao=566863>. Acesso em: 15 Nov. 2014.
} 


\section{Revista Letras Raras}

ISSN: 2317-2347 - Vol. 7, Ano 4, No 2 - 2015

estrangeira, passe a ser oral, como medida de forçar transformações na estrutura curricular das escolas. Do exposto, fica a indagação: qual seria a repercussão dessa medida? Possivelmente, o insucesso dos resultados dos estudantes seria divulgado em canais midiáticos, implicando a continuidade de práticas pedagógicas pouco efetivas e a implementação de medidas paliativas.

\section{O ENSINO DE LÍNGUA INGLESA COMO POLÍTICA LÍNGUÍSTICA}

Pensamos ter deixado claro que as políticas linguísticas nem sempre adquirem visibilidade ou são publicizadas. Segundo Oliveira (2013, p. 1), elas aparecem por vezes diluídas dentro de outras políticas como a educacional, por exemplo, ou tornam-se invisíveis pela própria naturalização das questões linguísticas. A hegemonia do inglês é uma dessas políticas (im)percebíveis que se impõem pelas forças política e econômica.

Se observarmos com olhar especialmente para a internacionalização das Instituições de Ensino Superior - IES brasileiras e as medidas adotadas pelo governo federal em prol da aprendizagem da língua inglesa no âmbito do ensino superior, desde a implantação do CsF, podemos entender que tais medidas são também políticas linguísticas. A eventual invisibilidade dessas políticas é intencional, uma vez que estão a serviço de políticas públicas maiores, cuja divulgação é de interesse do Estado. Além disso, elas surgem em circunstâncias adversas, agem como atenuantes de uma carência sem solução prevista. Neste viés, Luna e Senhem (2013, p. 452) assinalam que "programas de mobilidade internacional podem ser frutos de políticas linguísticas quando a ação da mobilidade é organizada, planejada e executada sob preceitos de interesse de uma coletividade". 


\section{Revista Letras Raras}

ISSN: 2317-2347 - Vol. 7, Ano 4, No 2 - 2015

Outro argumento é o fato de que, em 2013, o Governo Federal decidiu excluir a parceria com Portugal no programa CsF, justificando que o país tem idioma comum ao dos estudantes brasileiros e que o cancelamento estimularia a aprendizagem de outras línguas. Com essa estratégia, também ficou evidente que há línguas privilegiadas em detrimento de outras no bojo do programa. Este nível de política linguística caracteriza, segundo Spolski (2004) e Shohamy (2006), uma conexão importante entre os discursos circulantes sobre línguas e seus falantes com as relações de poder da sociedade.

Ainda, se pensarmos em quais línguas favorecem o processo de internacionalização e de que maneira isto ocorre, como sugere Oliveira (2013b), seriam encontradas várias razões para apontar a língua inglesa. As mensagens que circulam na mídia confirmam isso. Entretanto, a conjuntura mundial requer formas alternativas de ensino e outros olhares para as línguas, que considerem a diversidade local e a conectividade global. Muito embora o discurso midiático em prol de um ensino de qualidade soe unânime e legítimo, ele apenas representa uma entre outras maneiras atuais de promover o ensino efetivo de línguas estrangeiras, e dar boas razões para uma política de internacionalização.

\section{CONSIDERAÇÕES FINAIS}

Ao final deste artigo, cabem algumas considerações sobre o trabalho realizado, cujo objetivo foi examinar as manifestações discursivas acerca do ensino da língua inglesa na educação básica em textos publicitários e a legislação vigente que normatizam este ensino para caracterizar o status do idioma frente ao processo de internacionalização do ensino superior instituído no país.

O levantamento de dados revelou que o estatuto diferenciado adquirido pela língua inglesa nos últimos tempos traz a necessidade de que as concepções a respeito das línguas estrangeiras sejam analisadas por todos os envolvidos no sistema 


\section{Revista Letras Raras}

ISSN: 2317-2347 - Vol. 7, Ano 4, No 2 - 2015

educacional, a fim de que se possa repensar o modo como essa língua vem sendo ensinada nas escolas de ensino regular.

A análise dos dados permitiu verificar que o CsF provocou a exposição dos resultados da aprendizagem de línguas estrangeiras, em especial do inglês, pelos egressos da educação básica. Esta é uma realidade positiva se pensarmos que tem promovido o debate e que algumas iniciativas promissoras no âmbito governamental já foram sinalizadas. Entretanto, não é construtiva se os discursos midiáticos forem tomados como parâmetros absolutos para embasar e definir políticas públicas educacionais e políticas linguísticas, carentes de ampla reflexão e de considerações acerca de dois aspectos importantes: o papel das línguas no mundo; a sociedade e os sujeitos que se espera formar a partir da educação escolarizada.

\section{REFERÊNCIAS}

ANDREOTTI, V. O educação para a cidadania global - soft versus critical. Sinergias diálogos educativos para a transformação social | Dezembro, 2014. n.o 1

ALMEIDA FILHO, J. C. P. Quatro Estações no Ensino de Línguas. Campinas, SP Pontes Editores, 2012.

BAKHTIN, M. Marxismo e filosofia da linguagem. São Paulo: Hucitec, 1999.

BRASIL. Lei no 9.394, de 20 de dezembro de 1996. Estabelece as Diretrizes e Bases da Educação Nacional. Diário Oficial [da] República Federativa do Brasil. Brasília, DF, v. 134, n. 248, 23 dez. 1996. Seção 1, p. 27834- 27841.

BRASIL. Lei n. 11.161, de 2005. Dispõe sobre o ensino da língua espanhola. Diário Oficial [da] República Federativa do Brasil. Brasília, DF, 08 ago. 2005, p. 1.

BRASIL. Lei no 11.274, 6 de fevereiro de 2006. Altera a redação dos art. 29, 30, 32 e 87 da Lei no 9.394, de 20 de dezembro de 1996. Estabelece as diretrizes e bases da educação nacional, dispondo sobre a duração de 9 (nove) anos para o ensino fundamental, com matrícula obrigatória a partir dos 6 (seis) anos de idade. Diário Oficial da União. 7 fev. 2006. Seção 1, p.1. 


\section{Revista Letras Raras}

ISSN: 2317-2347 - Vol. 7, Ano 4, No 2 - 2015

BRASIL. Decreto n. 7642 de 13 de dezembro de 2011. Diário Oficial [da] República Federativa do Brasil. Poder Executivo, Brasília, DF, 14 dezembro de 2011. Seção 1. Página 7.

BRASIL. Ministério da Educação. Secretaria de Ensino Médio e Tecnológico. Portaria n. 1466 de 18 de dezembro de 2012. Diário Oficial [da] República Federativa do Brasil. Poder Executivo, Brasília, DF, n. 244.19 dezembro de 2012, Seção 1 páginas 28/29.

BRASIL. Comissão especial destinada a promover estudos e proposições para a reformulação do ensino médio - CEENSI. Projeto de Lei n. 6840 de 2013. Disponível em:<

http://www.camara.gov.br/proposicoesWeb/fichadetramitacao?idProposicao $=602570$ >. Acesso em: 17 fev. 2015.

BRASIL. Ministério da Educação. Secretaria de Ensino Médio e Tecnológico. Portaria n. 973 de 14 de dezembro de 2014. Diário Oficial [da] República Federativa do Brasil, Poder Executivo. Brasília, DF, n. 222. Seção 1 páginas 11/12.

CALVET, L.J.. As políticas linguísticas. Prefácio Gilvan Muller de Oliveira; tradução Isabel de Oliveira Duarte, Jonas Tenfen, Marcos Bagno. São Paulo: Parábola Editorial: IPOL, 2007.

DUBOC, A. P. M. A avaliação da aprendizagem de língua inglesa segundo as teorias de letramentos. São Paulo. Tese de mestrado em Letras pela Universidade de São Paulo, 2007.

DUBOC, A. P. M. Letramentos críticos nas Brechas da Formação de professores de inglês. São Paulo. Tese de doutorado em Letras pela Universidade de São Paulo, 2012.

EDMUNDO, E.S.G. Letramento crítico no ensino de inglês na escola pública: planos e práticas nas tramas da pesquisa. Campinas: Editora Pontes, 2013.

FIORIN, j. L. Linguagem e Ideologia. 8. ed. São Paulo: Ática, 2004.

FREIRE, P. Pedagogia da autonomia: saberes necessários à prática educativa. São Paulo: Paz e Terra, 1998.

GADOTTI, M. Qualidade na educação: uma nova abordagem. Anais do Congresso de Educação Básica. Florianópolis: Rede Municipal de Florianópolis, 2013.

GIMENEZ, T. et al. Referências recentes sobre língua inglesa, mídia e escola no contexto brasileiro. Linguagem \& Ensino, Vol. 9, No. 1, 2006 (251-266). 


\section{Revista Letras Raras}

ISSN: 2317-2347 - Vol. 7, Ano 4, No 2 - 2015

JORDÃO, C. M. A. Língua inglesa como "commodity": Direito ou obrigação de todos? In: ROMANOWSKI, J.P.; MARTINS, P.L.O., JUNQUEIRA, S.R.A. (orgs) Conhecimento local e conhecimento universal: a aula e os campos de conhecimento. v.3. Curitiba, Champagnat, 2004.

LEVY, P. A esfera pública do século XXI. Disponível em: < http://escoladeredes.net/group/bibliotecapierrelevy/forum/topics/a-esfera-publicado-seculo-xxi >. Acesso em: 20 Jan. 2015.

LIBÂNEO, J.C. Considerações críticas sobre o documento "diretrizes do pacto pela educação: reforma educacional goiana. Disponível em:< http://www.sintego.org.br/midias/banners/13122013082557.pdf?PHPSESSID=ffafb29f ea0424b8dd597030e7fbc4cc>. Acesso em: 17 fev. 2014.

LUNA J.M.F.; SEHNEM, P.R. Erasmus e Ciência sem Fronteiras: considerações iniciais sobre mobilidade estudantil e política linguística RBPAE - v. 29, n.3, p. 445-462, set/dez. 2013.

MEC, 2009. Documento Referência: Conferência Nacional de Educação. Brasília: MEC

MENEZES DE SOUZA, L. M. T. O professor de inglês e os letramentos no século XXI: métodos ou ética?. In: JORDÃO et al (Org.). Formação "desformatada" práticas com professores de língua inglesa. Campinas, SP: Pontes, 2011, p. 279-303.

MOITA LOPES, L.P. A nova ordem mundial, os parâmetros curriculares nacionais e o ensino de inglês no Brasil: a base intelectual para uma ação política. In. BARBARA, L.; RAMOS, R.C.G. (orgs.) Reflexão e ações no ensino aprendizagem de línguas. Campinas: Mercado de Letras, 2003, p. 2957.

OLIVEIRA, A.F. Políticas públicas educacionais: conceito e contextualização numa perspectiva didática. In: OLIVEIRA, Adão Francisco de. Fronteiras da educação: tecnologias e políticas. Goiânia-Goiás: PUC Goiás, 2010.

OLIVEIRA, G. M. Políticas linguísticas como políticas públicas. 2013.

OLIVEIRA, G. M. Política linguística e internacionalização: a língua portuguesa no mundo globalizado do século XXI. Trabalhos em línguística aplicada. vol.52 no.2 Campinas July/Dec. 2013b.

POUZA, S.S. Mídia escrita e concepções de ensino/aprendizagem de inglês como língua estrangeira. Contexturas, Indaiatuba, n.5, p.127-152, 2000/2001. 


\section{Revista Letras Raras}

ISSN: 2317-2347 - Vol. 7, Ano 4, No 2 - 2015

RAJAGOPALAN, K. Por uma lingüística crítica: linguagem, identidade e a questão ética. São Paulo: Parábola editorial, 2003.

RODRIGUES. M.H.C. Gutenberg e o letramento do ocidente. Revista Educação e Linguagens, Campo Mourão, v. 1, n. 1, ago./dez. 2012.

SHOHAMY, E. Language policy: hidden agendas and new approaches. New York: Routledge, 2006.

SILVA, K. A.; SANTOS, L. I. S.; JUSTINA, O. D. Entrevista com Kanavillil Rajagopalan: ponderações sobre linguística aplicada, política linguística e ensino-aprendizagem. Estudos Linguísticos, Sinop, v. 4, n. 8, p. 75-81, jul./dez. 2011. Disponível em: http://projetos.unemat-net.br/revistas_eletronicas/index.php/norteamentos

SPOLSKY, B. 2004. Language Policy. Cambridge, Cambridge University Press.

TAKAKI, N. H. Letramentos na sociedade digital: navegar é e não é preciso. Tese de doutorado em Letras pela Faculdade de Letras da USP, 2008.

Recebido: em 30 de Agosto de 2015 Aceito: em 01 de outubro de 2015 